\title{
O direito à educação das pessoas privadas da liberdade: uma pesquisa-ação
}

\author{
The right to education for people deprived of their liberty: a research-action \\ El derecho a la educación de las personas privadas de libertad: una investigación-acción
}

Recebido: 28/01/2022 | Revisado: 01/02/2022 | Aceito: 16/02/2022 | Publicado: 25/02/2022

\author{
Thais Barbosa Passos \\ ORCID: https://orcid.org/0000-0003-3093-240X \\ Universidade de São Paulo, Brasil \\ E-mail: thabpassos@gmail.com
}

\begin{abstract}
Resumo
A pesquisa realizada teve como objetivo fomentar a produção textual das pessoas presas na Província da Lunda Norte, em Angola, a fim de identificar seus elementos constitutivos, as narrativas predominantes e o uso da competência escritora tanto na afirmação da identidade quanto na afirmação de direitos. Entendendo que Educação se faz ao longo da vida, em todos os tempos, todos os espaços e que a escrita das pessoas presas constitui uma Literatura Carcerária ainda a ser tematizada pela pesquisa acadêmica, desenvolvemos o estudo por meio da oferta de oficinas literárias para posterior análise dos materiais produzidos. Pensar o direito à educação na prisão significa refletir sobre sua contribuição para a vida dos encarcerados e da sociedade em geral, a oferta de atividades educacionais nos espaços de privação da liberdade guarda especificidades que a diferenciam de outros espaços. É uma oportunidade de socialização, na medida em que oferece aos participantes novos referenciais, possibilidade de reconstrução da identidade e de resgate da cidadania perdida. Por meio do desenvolvimento da pesquisa confirmamos a hipótese que, em uma população prisional com acesso somente à leitura da bíblia e, pouco estímulo à leitura e a escrita, o contexto de encarceramento, por si só, é capaz de produzir uma epistemologia que se traduz em narrativas de interesse para a área da Educação.
\end{abstract}

Palavras-chave: Direito; Educação; Prisão.

\begin{abstract}
The research conducted had the objective of promoting the textual production of prisoners in the Province of Lunda Norte, Angola, in order to identify its constitutive elements, the predominant narratives and the use of writing skills both in the affirmation of identity and in the affirmation of rights. Understanding that education is done throughout life, at all times, in all spaces, and that the writing of prisoners constitutes a Prison Literature yet to be thematized by academic research, we developed the study by offering literary workshops for later analysis of the materials produced. Thinking about the right to education in prison means reflecting on its contribution to the lives of prisoners and society in general; the offer of educational activities in spaces of deprivation of freedom has specificities that differentiate it from other spaces. It is an opportunity for socialization, in the sense that it offers the participants new references, the possibility of identity reconstruction, and the rescue of lost citizenship. Through the development of the research, we confirmed the hypothesis that, in a prison population with access only to Bible reading and little stimulus to reading and writing, the context of incarceration, by itself, is capable of producing an epistemology that translates into narratives of interest to the field of Education.
\end{abstract}

Keywords: Law; Education; Prison.

\section{Resumen}

La investigación realizada tuvo como objetivo incentivar la producción textual de los presos de la Provincia de Lunda Norte, Angola, para identificar sus elementos constitutivos, las narrativas predominantes y el uso de la escritura tanto en la afirmación de la identidad como en la afirmación de los derechos. Entendiendo que la educación se hace a lo largo de la vida, en todos los tiempos y espacios y que la escritura de los presos constituye una Literatura Carcelaria aún no tematizada por la investigación académica, desarrollamos el estudio ofreciendo talleres literarios para el posterior análisis de los materiales producidos. Pensar en el derecho a la educación en la cárcel significa reflexionar sobre su contribución a la vida de los presos y de la sociedad en general; la oferta de actividades educativas en los espacios de privación de libertad tiene especificidades que la diferencian de otros espacios. Es una oportunidad de socialización, ya que ofrece a los participantes nuevas referencias, la posibilidad de reconstruir la identidad y rescatar la ciudadanía perdida. A través del desarrollo de la investigación confirmamos la hipótesis de que, en una población carcelaria con acceso sólo a la lectura bíblica y poco estímulo a la lectura y escritura, el contexto de encarcelamiento, por sí mismo, es capaz de producir una epistemología que se traduce en narrativas de interés para el área de Educación.

Palabras clave: Derecho; Educación; Prisión. 


\section{Introdução}

O problema da pesquisa consiste em introduzir em uma prisão de Angola a prática da leitura e da escrita como corolário para a emergência de uma Literatura Carcerária que, a rigor, não existe nos estabelecimentos prisionais daquele país.

Os antecedentes desta experiência são calcados na prática brasileira de utilizar a leitura e a escrita tanto para redução da pena quanto fomento ao hábito de leitura e elevação da cultura geral para desenvolver o processo de conscientização nos presos, conforme experiência pioneira desenvolvida por Salete Van der Poel, no estado da Paraíba, em 1979.

Levantamentos preliminares realizados no campo de pesquisa indicaram que em doze meses - de agosto de 2018 a agosto de 2019 - os presos da amostra não leram nenhum livro, além da bíblia e raros escreveram alguma coisa, o que caracteriza o referido estabelecimento penitenciário como um espaço possível para a produção de uma Literatura Carcerária.

Pensando em que medida a experiência brasileira de introduzir a leitura e a escrita como componente da Execução Penal pode ser viabilizada em um contexto estrangeiro que não conhece tais práticas. Temos por hipótese que em uma população prisional com escasso acesso ou estímulo à leitura e à escrita, suas primeiras manifestações escritas trarão as evidências de uma Literatura Carcerária cuja epistemologia é determinada pela situação de encarceramento.

No Brasil, de acordo com a Lei nº 7.210, de 11 de julho de 1984, Lei de Execução Penal, o objetivo da execução penal é “... efetivar as disposições de sentença ou decisão criminal e proporcionar condições para a harmônica integração social do condenado e do internado".

Em Angola, a Lei nº 8, de 29 de agosto de 2008, Lei Penitenciária, tem por objetivo: “... garantir a execução das penas e medidas privativas de liberdade impostas pelos tribunais e visa à reintegração social dos reclusos, preparando-os para no futuro conduzirem a sua vida de modo socialmente responsável”. (Angola, 2008, p. 2325).

Sendo assim, em ambos os países a execução da pena compreende a reintegração social, para tanto consideramos a oferta de estudo e trabalho, condições sine qua non para cumprir com os objetivos das referidas leis.

Compreendemos a reintegração social como um processo pelo qual se procura associar a elevação da escolaridade e a formação profissional, de maneira a promover o ingresso ao mundo do trabalho, após o cumprimento da pena privativa de liberdade. (Carvalho, 2019).

\section{Metodologia}

A metodologia como modo de conduzir a pesquisa pode ser interpretada como conhecimento geral necessário para a pesquisadora se orientar no processo de investigação, sendo assim, o estudo da metodologia exerce importante função de ordem pedagógica à pesquisa científica.

As fontes primárias correspondem ao material a ser efetivamente analisado, consiste na produção textual dos presos que participaram do experimento pedagógico, cujos elementos são a gênese da Literatura Carcerária.

As fontes secundárias resultaram do processo de coleta de dados por meio da aplicação de questionários à totalidade da população prisional do estabelecimento pesquisado e de observação direta por parte da pesquisadora.

As fontes terciárias para fundamentação legal da pesquisa foram as leis penitenciárias de cada país, que constituem os marcos normativos para todos os aspectos da execução penal e do tratamento de presos no Brasil e em Angola.

Para viabilizar a produção da escrita e da leitura foi necessária a obtenção de autorização do Ministério do Interior e colaboração tanto da direção quanto da equipe técnica do Estabelecimento Prisional de Cacanda, o que possibilitou organizar a pesquisa-ação intitulada curso de Alfabetização Científica, executado no período de agosto a novembro de 2019, com a participação de vinte e seis homens privados de liberdade.

Sobre o termo Alfabetização Científica, Silva et al. (2022, p. 4), afirma que: 
... Este é usualmente empregado para designar um ensino de ciências voltado para a formação de um cidadão. Esperase, portanto, que ... os estudantes possam dominar basicamente determinados conhecimentos científicos, associados a uma concepção de ciência como atividade humana, social e cultural, de modo a utilizar tais conhecimentos para uma análise crítica e tomada de decisão frente as mais variadas situações sociais e ambientais com as quais se deparam.

É esta realidade que leva à caracterização da pesquisa-ação, proporcionamos que algumas pessoas custodiadas produzissem sua própria escrita para que pudéssemos identificar o potencial pedagógico implícito nas produções a que estamos denominando Literatura Carcerária.

Com acesso restrito às tecnologias da informação e da comunicação (TIC), principalmente telefonia, internet e computador, escrever à mão é o recurso mais utilizado por pessoas presas em suas comunicações de toda natureza. Para estas, a leitura e a escrita ainda são funcionais, o que não ocorre com pessoas da mesma idade e da mesma escolaridade que estão em liberdade e para as quais escrever à mão deixou de ser funcional.

A oferta de oficinas literárias para a população prisional, de uma penitenciária situada fora do Brasil, possibilitou identificar pontos sensíveis na execução penal internacional e na política criminal, apontando que a Educação em Direitos é uma demanda que deve ser implementada antes, durante e depois do cumprimento da pena.

O local de nossa investigação é o Estabelecimento Prisional de Cacanda, situado na Província de Lunda Norte, em Angola, país localizado ao Sul do continente africano.

A Direção Provincial do Serviço Penitenciário de Lunda Norte foi inaugurada em 3 de dezembro de 1993, no âmbito da política de preenchimento do Quadro Orgânico da Delegação Provincial do Ministério do Interior da Lunda Norte.

A estrutura inicial foi reconhecida oficialmente mediante o Despacho $\mathrm{n}^{\circ} 211$, de 16 de dezembro de 1997, adaptada a título provisório, a um armazém da antiga Companhia de Diamantes de Angola, sem condições específicas para um Estabelecimento Prisional, o que ocasionou grandes dificuldades de ordem técnica e material.

O estabelecimento prisional atual está dividido em três blocos, A, B e C para abrigar os homens, cada bloco conta com dezenove celas, a capacidade de cada cela é de oito pessoas. No bloco A estão aqueles que foram condenados (já julgados) ou detidos (aguardando julgamento) por crime contra a pessoa; no bloco B aqueles que foram condenados ou detidos por crime contra a propriedade; e, no bloco $\mathrm{C}$, estão aqueles que foram condenados ou detidos por crime contra a tranquilidade pública. O bloco que abriga as mulheres tem capacidade para 25 pessoas.

No estabelecimento prisional de Cacanda, lócus da presente pesquisa, havia, em agosto de 2019, 10 mulheres e 501 homens, totalizando 511 pessoas privadas da liberdade, cerca de 100 presos eram estrangeiros, destes $90 \%$ advindos da República Democrática do Congo, país fronteiriço.

Em agosto de 2019 os blocos A e B estavam com 172 presos em cada um deles e o bloco C tinha 165 presos, o que resulta em 53 homens a mais do que a capacidade do estabelecimento. Já o bloco feminino estava com 10 mulheres, abaixo da capacidade.

Depreende-se que os homens que se encontravam privados de liberdade em Cacanda ocupavam o mesmo espaço e eram divididos pelo delito cometido independente de já terem sido julgados ou estarem aguardando julgamento, isto é, com a possibilidade de não serem condenados.

Angola foi formada pelas populações de origem bantu, por meio de nove etnias, quais sejam: Bakongo, Nganguela, Nyaneka-Humbe, Herero, Cokwe, Ovambo, Ambundo, Umbundu e Xindonga. Cada um destes povos possui a sua própria língua e, por isso são denominados grupos etno-linguísticos.

Quanto à escolaridade em Angola é dividida em Ensino Primário que vai da $1^{\mathrm{a}}$ a $6^{\mathrm{a}}$ classe, Ensino Secundário $-1^{\circ}$ ciclo: da $7^{\mathrm{a}}$ a $9^{\mathrm{a}}$ classe e Ensino Secundário $-2^{\mathrm{o}}$ ciclo: da $10^{\mathrm{a}}$ a $12^{\mathrm{a}}$ classe.

Ao desenvolvermos a pesquisa-ação de cunho pedagógico em um contexto no qual impera, muitas vezes, a 
truculência, a vigilância, a desconfiança, o poder, o cumprimento de normas rígidas e a subserviência, definimos como estratégia inicial convencer as autoridades locais quanto à importância de promover atividades educativas com vistas à manutenção da segurança, diminuição do ócio e a promessa de que contribuiríamos com a penitenciária por meio das doações de livros e materiais didáticos.

Ressaltamos a necessidade de elaborar estratégias para obter autorização a fim de promovermos oficina literária dentro do contexto prisional, foram muitos os entraves encontrados, desde a falta de espaço físico, material didático ao receio de indisciplina. Para tanto, providenciamos a doação de livros literários, cadernos, folhas e canetas para cada participante, tal estratégia configurou-se certeira e passamos para a próxima etapa que foi a entrega de questionários.

Antes de distribuirmos os questionários, explicamos do que se tratava, em seguida, indagamos para cada um se estavam de acordo em responder de livre e espontânea vontade. A cada um dos participantes foi explicado o roteiro de questões para que respondessem por escrito ou oralmente, àqueles que não eram alfabetizados.

Após o preenchimento do questionário por parte dos presos, a fim de identificarmos, principalmente, se desejavam ou não participar da atividade proposta, decidimos por formar uma turma destinada aos reclusos que já tinham sido condenados, liam e escreviam e, sobretudo, demonstraram interesse em participar da atividade proposta.

Analisados e tabulados os dados de toda a população prisional que constitui o universo da pesquisa, deliberou-se também que a amostra privilegiaria aqueles que estavam estudando quando em liberdade e que interromperam a escolarização, possibilitando, desta forma, melhor potencial para aproveitamento das atividades a serem desenvolvidas e, possivelmente, estimularia a retomada dos estudos depois de readquirir a liberdade.

Assim, a amostra foi constituída por vinte e seis homens presos, todos presos condenados, que receberam pela primeira vez a condenação.

Assim como no Brasil, a maior parte das pessoas reclusas em Cacanda apresentavam baixa escolaridade, histórico de evasão escolar, com a média de idade entre 30 e 45 anos, baixa renda ou desempregadas antes de serem presas e pouca qualificação profissional.

Algumas constatações sobre o perfil da população de Cacanda, de acordo com o questionário realizado com a totalidade das pessoas privadas da liberdade:

1. grande parte da população carcerária nunca estudou ou interrompeu muito cedo os estudos;

2. a maior parte da população parou de estudar por falta de condições financeiras;

3. o estabelecimento carece de espaço físico destinado à sala de aula, pois há apenas duas salas pequenas e improvisadas com capacidade máxima para 20 alunos, não atingindo em 10\% a população total de Cacanda;

4. necessidade de intervenção do Ministério do Interior, no que se refere à obrigatoriedade de documento oficial para a expedição de certificação dos alunos que concluem as etapas finais de ensino na prisão;

5. possibilidade de ampliação da oferta de escolarização da $6^{\mathrm{a}}$ para à $12^{\mathrm{a}}$ classe nos estabelecimentos situados fora da capital, promovendo, assim, a conclusão do ensino geral;

6. necessidade de certificação e remuneração aos reclusos que ministram aula no Estabelecimento Prisionais.

O desenho teórico da pesquisa a caracteriza como uma pesquisa-ação, tal instrumento de pesquisa "consiste essencialmente em elucidar problemas sociais e técnicos, cientificamente relevantes, por intermédio de grupos em que se encontram reunidos pesquisadores, membros da situação-problema e outros atores e parceiros interessados na resolução dos problemas levantados ou, pelo menos, no avanço a ser dado para que sejam formuladas adequadas respostas sociais, educacionais, técnicas e/ou políticas”. (Thiollent, 2011, p. 7). 
Para Correa et al. (2018), a pesquisa-ação é estratégia de investigação, de interpretação, participação e transformação da realidade, caracterizada por dois tipos de objetivos: objetivo prático, voltado ao levantamento de soluções e possibilidades de ações relacionadas ao objeto de estudo; e o objetivo de conhecimento trata-se da obtenção de informações e ampliação de conhecimento no campo da ciência.

O referido instrumento de pesquisa nos permitiu, mediante ao diagnóstico situacional, promover a busca por soluções aos problemas vivenciados pelos participantes, para os quais os procedimentos convencionais de pesquisa teriam pouca ou nenhuma possibilidade de ação. Pois, “... os aspectos estruturais da realidade social não podem ficar desconhecidos, a ação só se manifesta num conjunto de relações sociais estruturalmente determinadas. " (Thiollent, 2011, p. 15).

O trabalho de campo - para observação, anotações, registros e organização das atividades - se orientou pelas propostas de Van Der Poel (2018), a pioneira na prática transformadora de educação em presídios, para construção de uma sociedade justa e que respeite os direitos humanos.

A tarefa da revisão bibliográfica se deu durante todo o processo de pesquisa, principalmente na análise dos dados coletados pois, a temática de pesquisa coloca em evidência bibliografia especializada da qual foi necessária maior apropriação pela pesquisadora. Esta se refere aos conceitos de Literatura de Testemunho (Seligmann-Silva, 1998, 2003, 2012) e Literatura de Reconhecimento (Honneth, 2003) como elementos de análise da produção textual.

Iniciamos a pesquisa-ação e definimos que seriam três encontros semanais presenciais, com duas horas e meia cada um, permeado por roda de leitura, roda de conversa, debates e produções textuais. O material utilizado com os participantes consistiu nos livros Sarau Asas Abertas: as mulheres poetas: penitenciária feminina da capital (2019) e os dois volumes do livro Contos tirados de mim, da Editora Giostri (2016). Obras literárias de poesia e contos escritos por pessoas presas.

A forma de avaliação foi realizada por uma autoavaliação, na qual buscamos por meio da observação, sensibilidade e acompanhamento sistemático de cada participante identificar os avanços adquiridos mediante o curso ofertado.

Considerando que a análise de conteúdo do tipo análise categorial é uma técnica de análise de comunicações para examinar o que foi dito em entrevistas ou observado pela pesquisadora, esta análise serve para ajudar a pesquisadora a ultrapassar as incertezas e descobrir o que foi questionado. (Silva \& Fossá, 2015).

A média de idade da turma era de 30 anos, vinte e quatro nascidos em Angola e dois na República Democrática do Congo. Todos condenados pela primeira vez, sendo seis estudantes presos há menos de um ano e os demais com três anos ou mais de privação, até novembro de 2019.

No que se refere à escolaridade, a maioria deles não concluiu a $9^{\mathrm{a}}$ classe, o que aqui no Brasil denominamos, Ensino Fundamental II.

Quanto aos motivos que os fizeram parar de estudar, a principal motivação se deu por motivo financeiro. Aqui constatamos que a questão financeira também carecia de atenção da nossa parte, pois o ensino geral em Angola é, em sua maioria, pago e as instituições gratuitas não atendem todas as províncias do país, ou seja, mesmo com algumas escolas públicas, há necessidade de recursos financeiros para o deslocamento até elas.

Quanto aos delitos, dezesseis deles foram condenados pela prática de crimes cometidos contra pessoas e dez pela prática de crimes cometidos contra propriedade, cuja média de condenação é de nove anos. Não realizamos um aprofundamento de qual crime cada estudante cometeu, até porque não fazia parte do escopo da pesquisa.

O primeiro encontro com os participantes foi permeado por muita observação, curiosidade, timidez e silêncios. Iniciei explicando que eu era brasileira e estava desenvolvendo minha pesquisa de doutorado, falei da proximidade do meu orientador com Angola, motivo que me possibilitou estar lá.

A primeira pergunta foi se eu não tinha medo de estar naquele lugar, por ser mulher e eles homens perigosos, respondi que não e que já tinha realizado atividade semelhante no Brasil com adultos e adolescentes privados da liberdade. 
A pergunta seguinte foi se meu marido estava em Angola também e se ele havia me autorizado, ao que eu respondi que não tinha marido no Brasil (sou casada com uma mulher, mas não era o caso de expor minha vida pessoal naquele momento) e esclareci que mesmo casada continuaria tomando as minhas próprias decisões, momento em que causei espanto em todos os presentes e um deles afirmou que se eu fosse angolana isso não seria possível. Encerrado esse assunto, expliquei que necessitaria da concordância e autorização de cada um quanto à publicização do conteúdo desenvolvido por eles, obtendo a concordância de todos.

A apresentação dos relatos verbais e escritos dos participantes da pesquisa compõem o que denominamos Literatura Carcerária. Ao fim da primeira semana de encontro, repleta por muitos textos e diálogo, solicitei que me dissessem ou escrevessem suas impressões e qual era a expectativa deles em relação aos nossos encontros, conforme segue:

Eu espero deste curso aprender mais coisas que eu não conheço na vida cotidiana e ganhar mais experiência. Será professora Thais que nesta vida tem saída ou não tem saída, professora? Ezequiel. (Informação verbal/escrita)

Pacavira respondeu: Sobre o curso tenho a expectativa de ser um instruído, com sucesso durante o tempo em que vou enfrentar esse processo. Isso para dizer que gostaria que a senhora professora Thais não canse em nos trazer conhecimento porque a sua presença me satisfaz muito na minha estadia cá como preso. Vivo numa sobrecarga de pensamento, pensando o tempo de prisão que me foi dado, o tempo fora dos familiares, o atraso de outras formações que deveria enfrentar. (Informação verbal/escrita)

Pacheco escreve: Espero adquirir conhecimento para quando eu sair deste lugar, e em liberdade não ter problemas ao enfrentar a sociedade, porque na cadeia eu ainda não aprendi isso, professora. (Informação verbal/escrita)

A gênese da literatura carcerária é a produção de relatos, narrativas e histórias de vida de autoria das pessoas privadas de liberdade. Evidenciamos a importância da leitura, da escrita e dos estudos como fatores capazes de reduzir os prejuízos acarretados pela privação da liberdade, pelos efeitos positivos que trazem.

Sobre esses escritos destaco mais alguns, após o primeiro mês de curso:

Bumba: Agora compreendo que a sociedade realmente precisa de nós. Eu tenho a esperança de um dia ser famoso, porque eu tenho o sonho de ser músico. Professora Thais eu a agradeço pelo conhecimento que a senhora me dá de graça, porque a senhora nos dá tanto conhecimento. Muito obrigada pela ajuda de estar aqui para dialogar conosco. Falando sobre como foi esse mês de curso, foi totalmente bom, aprendi a pensar além, por causa deste curso. Professora eu não tenho como te agradecer, estando na prisão eu estou a sofrer, mas estando cá a prestar atenção neste curso agora eu consigo falar, escrever e repensar a história da minha vida. Eu sou Gabriel Bumba, eu tinha um olhar muito péssimo de mim mesmo estando privado de liberdade, agora eu tenho um novo olhar de mim mesmo porque eu aprendi a me perdoar. Este curso está me fazendo compreender que o caminho para uma vida digna é a educação, que aqui está sendo dada a mim e de graça pela Professora. Estou a ganhar um novo olhar e um novo pensar e tendo sempre em vista que assim estou a lutar por mim mesmo, não penso mais na prisão e nas coisas tristes que vivo aqui. Muito obrigada por me ensinar que eu tenho direitos na cadeia e fora dela. (Informação verbal/escrita)

Mubi relata: Como nós aqui no nosso país estivemos por muito tempo em guerra, algumas pessoas não estudaram e outras não tiveram possibilidade financeira para concluir os estudos. Assim, aproveitamos esse curso para lutar e recuperar o tempo perdido, para mudar nossos caminhos antigos e percorrermos novos caminhos por meio dos ensinamentos da Professora Thais. Muito obrigada pela sua presença no meio de nós e por tudo o que temos aprendido Professora. Antes de eu ser preso os outros estudavam e trabalhavam, mas eu estava atrás na vida escolar e por isso eu fui preso, mas agora estou aprendendo. (Informação verbal/escrita)

Amado escreveu: Agradeço a oportunidade que nos foi concedida de estarmos junto à professora Thais que nos ensina o que não sabemos, nos permite ouvir poesias que antes nunca pensamos ouvir. (Informação verbal/escrita) 
A análise do conteúdo humano das produções literárias, de interesse mais acadêmico, se deu por meio da Teoria do Reconhecimento e da Literatura de Testemunho, que possibilitou apropriação do universo simbólico dos escritos, identificação das suas motivações, das suas representações e de seus anseios.

As ponderações levantadas se enquadram no âmbito do estudo realizado, sendo de grande pertinência, bem como oferecendo os instrumentos necessários para a análise das produções, considerando os sujeitos nelas envolvidos, seus objetivos e resultados.

Aplicar este corpus de conhecimentos para o desbravamento de uma realidade que, anteriormente, não considerava a Educação como espaço de diálogo e produção entre outros, afigura-se como inovação metodológica, especialmente por aplicarse metodologia de pesquisa já consagrada numa amostra sobre a qual ainda não incidiram fatores capazes de influenciar no resultado de sua produção escrita.

\section{Resultados e Discussão}

O problema da pesquisa consistiu em responder em medida a experiência brasileira de introduzir a leitura e a escrita como componente da Execução Penal pode ser viabilizada em um contexto estrangeiro que não conhece tais práticas?

Os antecedentes desta experiência são calcados na prática brasileira de usar a leitura e a escrita tanto para o fomento ao hábito de leitura e elevação da cultura geral quanto para redução da pena.

A hipótese comprovada foi a de que em uma população prisional com escasso acesso e estímulo à leitura e à escrita, as manifestações textuais trouxeram as evidências de uma Literatura Carcerária cuja epistemologia foi determinada pela situação de encarceramento.

Nesta pesquisa buscamos promover mudanças de perspectiva sob a ótica do diálogo, do respeito, da ética, da alteridade e da responsabilização, fazendo com que cada participante conseguisse perceber que é possível vislumbrar um futuro extramuros.

A investigação conduzida no estabelecimento prisional de Cacanda, com a realização de saraus e oficinas para a produção textual entre as pessoas presas é um elemento da literatura carcerária nos moldes dos trabalhos de Van Der Poel (2018) e Pires (2018), assim como o emprego da Teoria do Testemunho de Selligman-Silva (1998, 2003, 2012) e da Teoria do Reconhecimento de Honneth (2003), pois, trata-se de uma nova forma de se conduzir uma pesquisa no sentido de explorar novos campos e produzir novos conhecimentos a fim de tratar conhecidos problemas.

Ao nos valermos da análise de conteúdo como uma técnica assessora da pesquisa-ação, quando apuramos as categorias finais a partir dos dados coletados com os participantes das oficinas, evidencia-se a "privação de liberdade" enquanto condição na qual a pessoa é privada de sua liberdade e, também, de seus direitos, nota-se a necessidade de um "lugar de fala", de escuta e de protagonismo.

Compreendemos por epistemologia as etapas de assimilação e acomodação presentes no desenvolvimento ao longo da vida de cada sujeito, resultando na adaptação. Sendo assim, o ser humano assimila os dados que obtém do exterior e adapta esses dados à sua estrutura mental já existente.

O processo de modificação de si próprio é chamado de acomodação. Este esquema revela que nenhum conhecimento chega do exterior sem que sofra alguma alteração pelo indivíduo, sendo que tudo o que se aprende é influenciado por aquilo que já havia sido aprendido. A assimilação ocorre quando a informação é incorporada às estruturas já pré-existentes nessa dinâmica estrutura cognitiva, enquanto que a adaptação ocorre quando o organismo se modifica de alguma maneira de modo a incorporar dinamicamente a nova informação. Por fim, de um pensamento moderno que, buscando a síntese inusitada entre o biológico e o lógico-matemático, parece encontrar seus limites na desconstrução ainda mais inusitada a que tende sistematicamente todo o pensamento na atualidade: a de si mesmo se construindo de modo essencialmente esclarecido, Abreu 
et al. (2010).

Deste modo, podemos afirmar que a privação de liberdade gera no sujeito nova forma de compreender a realidade e produzir conhecimento, por meio de um processo de adaptação.

O curso de Alfabetização Científica ministrado aos participantes da pesquisa buscou relacionar a aprendizagem com o contexto social vivido, compreendendo-o como uma atividade ligada às características sociais e culturais do sujeito, de acordo com o contexto sociocultural em que aquelas pessoas estavam imersas.

Fana afirmou: Estou ampliando os meus conhecimentos, espero poder dar meu contributo na sociedade e despertar a mente de outras pessoas para que elas tenham os mesmos conhecimentos que foram despertados em mim pela Professora Thais. Porque em pouco tempo eu aprendi muita coisa e, principalmente, que nunca é tarde para aprender. Estou compreendendo que cada ser humano tem uma história de vida e que a cada dia que passa devemos entender e aprender com a nossa história em cada etapa da nossa vida. Percebo que apesar de estarmos cativos a Professora Thais nos deu a oportunidade e a possibilidade de compartilhar momentos da vida e isto é muito bom porque nos ajuda a desenvolver nossas habilidades e competências, contudo eu posso dizer que estou lutando para recuperar a minha autoestima e tenho sido encorajado pela professora a persistir. (Informação verbal/escrita)

Os saberes construídos no curso de Alfabetização Científica se realizaram a partir do conhecimento prévio de cada participante e a relação de reciprocidade que estabelecemos, ocasionando, assim, ambiente propício para a criação e expressão das ideias, valorização do saber de cada um sobre os temas tratados e a produção textual. Priorizamos a capacidade de comunicação e expressão de cada sujeito e não conteúdos curriculares.

Contribuímos para que o comportamento assumido pelos participantes fosse de reflexão e análise, privilegiando-se o diálogo, o questionamento, o respeito e as proposições, não existiam respostas certas ou erradas, mas a possibilidade de falar, escutar, ensinar e aprender proporcionando um novo modo de experienciar o aprendizado.

A partir das atividades promovidas nos nossos encontros, cujas temáticas foram capazes de relacionar diferentes áreas e esferas da vida, foi possível utilizar conceitos científicos integrando valores, decisões políticas e éticas sobre diferentes temáticas. De tal forma, a produção de conhecimento assume a sua importância científica e política. Política porque foi possível ensiná-los que aprender é uma maneira fundamental de resistir a privação da liberdade.

Fundamental vivenciar a empatia e flexibilizar o planejado, contando com a possibilidade de mudanças inesperadas, cancelamento dos encontros, imprevistos particulares como o acometimento de alguma dor ou doença, o recebimento de uma má notícia, visita cancelada ou a tentativa frustrada de ligação. Tudo isso impactava na interação com cada participante e a necessidade de motivá-los a seguir em frente mesmo diante de tantas adversidades.

Creio que compreendi a importância de cada participante e como cada um deles contribuiu no processo de construção de saberes, com eles aprendi muito e ensinei pouco, cumpri com a minha missão de conhecê-los e me fazer conhecer, a fim de garantir que a atividade promovida fosse um ato de liberdade e que o conhecimento compartilhado fosse significativo e nos tornassem pessoas melhores, primeiro para nós mesmas. "A visão de liberdade ... é a matriz que atribui sentido a uma prática educativa que só pode alcançar efetividade e eficácia na medida da participação livre e crítica dos educandos. " (Freire, 2010, p. 13).

\section{Considerações Finais}

Buscamos evidenciar o potencial das pessoas que participaram das atividades, o quanto elas me ensinaram, o quanto é possível diminuir o rótulo a elas impostos que uma vez presas serão para sempre criminosas e estarão fadadas ao ciclo perverso da reincidência.

Faz-se necessário que a sociedade compreenda que as pessoas privadas da liberdade são seres humanos, que merecem 
ser valorizados e reconhecidos positivamente, que possuem uma história de vida e todas as possibilidades de uma vida digna quando em liberdade. Que escrevem, imaginam, sonham e almejam uma vida melhor.

A reintegração social da pessoa pré-egressa depende das oportunidades e dos investimentos sociais realizados, não há que culpabilizar o indivíduo pelas mazelas sociais e econômicas impostas. A pessoa que cometeu um crime perdeu apenas o direito à liberdade, porém, não foi instituída uma política que assegure a ela os demais direitos dentro e fora da prisão, nem no Brasil tampouco em Angola.

O desenvolvimento da conscientização diz respeito ao estímulo que essa pesquisadora realizou no que se refere à valorização de cada participante, o entendimento da importância do estudo, bem como a possibilidade de vislumbrar um futuro diferente extramuros.

Acreditamos que a oferta de atividades educacionais são instrumentos capazes de evitar a reincidência penal e possibilitam mudança efetiva na vida das pessoas. Em Angola, especificamente no Estabelecimento Prisional de Cacanda, não havia a oferta de atividades educacionais complementares, a oferta de ensino regular só contemplava a alfabetização até a $6^{\mathrm{a}}$ classe e sem a garantia de certificação. Com a nossa atividade foi possível evidenciar as problemáticas, pensar nas possíveis soluções e apresentá-las às autoridades competentes visando à qualificação do atendimento educacional ofertado nas prisões do país.

Compreendemos existir uma interligação entre a teoria do testemunho (Selligmann-Silva, 1998, 2003, 2012), a teoria do reconhecimento (Honneth, 2003) e o tratamento da produção escrita de presos enquanto elemento constituinte da literatura carcerária. O conteúdo das produções pode ser caracterizado como literatura de testemunho (Seligmann-Silva, 2003). Esta abordagem privilegia o conteúdo humano implícito nesta temática, a percepção que o indivíduo tem da execução penal, os fatos que relata a representação que tem da instituição, dos seus agentes e de suas práticas, o que nos deu elementos para avaliar o grau de efetividade da política criminal e penitenciária em um dado momento histórico.

Podemos atestar que, mediante os encontros vivenciados, a empatia, a solidariedade, o respeito e a confiança se estabeleceram, conforme teoriza Honneth (2003). A literatura carcerária se relaciona com a inclusão dos sujeitos participantes enquanto pessoas possuidoras de direitos, auxiliando na autoestima, construção da sua verdadeira identidade, promovendo o protagonismo e, a possibilidade de construção de uma nova realidade. Rompendo-se assim com a política de silenciamento/apagamento imposta pela condição de recluso.

Portanto, quando a pessoa privada internaliza a liberdade, enxergando-se positivamente, o ciclo da opressão se transforma e retroalimenta-se de esperança. Recuperando a identidade, valorizando-se, a pessoa presa evidencia as suas potencialidades, desenvolvendo a capacidade de insurgir contra a realidade opressora do cárcere.

Temos consciência quanto a necessidade de desconstruirmos alguns mitos sobre raça, etnia, cor e cultura e sua relação com dificuldades de aprendizagem, à índole, ao caráter estigmatizante e discriminatório em relação a alguns tipos sociais, as amarras, condicionantes e determinantes que a estrutura social cria; sobretudo a dificuldade que temos de entender quem é o outro, entender quais os determinantes que o colocam naquela condição e que faz com deixemos de pensar de forma macro e estrutural e passemos, muitas vezes, para uma lógica de responsabilização dos indivíduos.

Talvez não precisemos esperar quarenta anos para ver a realidade prisional de Angola transformada. Em Pedagogia da indignação, Paulo Freire (2000) afirmou que se a educação sozinha não transforma a sociedade, sem ela, tampouco, a sociedade muda.

Por fim, sugerimos que o sistema prisional de Angola adote a remição da pena pelo estudo, pela leitura e pelo trabalho impactando positivamente na execução penal, a exemplo do que ocorre no Brasil; bem como que outros trabalhos acadêmicos no futuro se dediquem ao desenvolvimento da literatura carcerária em estabelecimentos prisionais que desconhecem tais práticas. 


\section{Agradecimentos}

À Coordenação de Aperfeiçoamento de Pessoal de Nível Superior - Brasil (CAPES) - que apoiou o presente trabalho. Aos participantes da pesquisa que tornaram possível a escrita da tese de doutoramento que culminou neste artigo.

Ao Prof. Me. Antonio Netto Junior, exemplo de ética, dedicação, empenho e solidariedade. Muito obrigada pela paciência, carinho e por sempre estar disposto a me orientar. A você minha eterna gratidão.

À Profa. Dra. Maria Salete Van der Poel, por ser minha mestra e inspiração.

\section{Referências}

Abreu, L. C. de. Et al. (2010). A Epistemologia Genética de Piaget e o Construtivismo. Revista Brasileira de Crescimento e Desenvolvimento Humano. 20(2): 351-60.

Angola. (2008). Diário Oficial da República de Angola. Lei n. ${ }^{\circ} \quad 8 / 2008$, de $29 \quad$ de $\quad$ Agosto. Lei Penitenciária. https://www.lexlink.eu/FileGet.aspx?FileId=1137863.

Brasil. (1984). Lei n. ${ }^{\circ}$ 7.210, de 11 de julho de 1984. Lei de Execução Penal. Disponível em: http://www.planalto.gov.br/ccivil_03/LEIS/L7210.htm. Acesso em: dez. 2021.

Carvalho, T. de. (2019). Métodos de Reeducação Prisional: uma abordagem sociológica. Luanda - Angola: Editora Acácias.

Coletivo Poetas do Tietê (Org.). (2019). Sarau asas abertas: penitenciária feminina da capital. (1ª ed.) São Paulo: Edições do Tietê.

Corrêa, G. C. G., De Campos, I. C. P. \& Almagro, R. C. (2018). Pesquisa-ação: uma abordagem prática de pesquisa qualitativa. Ensaios pedagógicos (2018). Sorocaba, SP. 2(1), 62-72. http://www.ensaiospedagogicos.ufscar.br/index.php/ENP/article/download/60/89.

Freire, P. (2000). Pedagogia da indignação: cartas pedagógicas e outros escritos. São Paulo: Editora UNESP.

Freire, P. (2010). Educação como prática da liberdade. Rio de Janeiro: Paz e Terra.

Honneth, A. (2003). Luta por reconhecimento: a gramática moral dos conflitos sociais. Trad.: Luis Repa. São Paulo: Ed. 34.

Passos, T. B. (2022). Literatura Carcerária: a pesquisa-ação no Estabelecimento Prisional de Cacanda, em Angola [Tese de doutorado não publicada]. Faculdade de Educação, Universidade de São Paulo.

Pires, T. de O. \& FREITAS, F. (Orgs.). (2018). Vozes do Cárcere: ecos da resistência política. Rio de Janeiro: Kitabu.

Poel, M. S. V. D. (2018). Vidas aprisionadas: relatos de uma prática educativa. Porto Alegre: Oikos.

Seligmann-Silva, M. (1998). Literatura de testemunho: os limites entre a construção e a ficção. Letras. Revista do mestrado em Letras da UFSM. Santa Maria, RS, UFSM; CAL, n. 16, jan./jul. pp. 9-37.

Seligmann-Silva, M. (2003). História, Memória, Literatura. O testemunho na era das catástrofes. Campinas: Editora da UNICAMP.

Seligmann-Silva, M. (2012). Escritas da violência. Vol. I. O testemunho. (Orgs.) Márcio Seligmann-Silva, Jaime Ginzburg \& F. Hardman. Rio de Janeiro: 7 Letras. 289 p.

Silva, A. H. \& Fossá, M. I. T. (2015). Análise de conteúdo: exemplo de aplicação da técnica para análise de dados qualitativos. Qualitas Revista Eletrônica, Campina Grande, PB, v. 16, n. 1, p. 1-14. http://revista.uepb.edu.br/index.php/qualitas/article/view/2113/1403.

Silva, A. da C. T. e, Ferreira, F. C. L. ., Santos, F. dos ., Silva, A. C. da, \& Fernandes, C. S. . (2022). Ensino por investigação e Ciências Forenses: possibilidades para a alfabetização científica. Research, Society and Development, 11(2), e36111225775. https://doi.org/10.33448/rsd-v11i2.25775.

Silva, R. da. (2011). Pedagogia Social: contribuições para uma teoria geral da Educação Social. v. 2. São Paulo: Expressão e Arte Editora.

Silva, R. da. (2017). Didática no Cárcere: entender a natureza para entender o ser humano e o seu mundo. São Paulo: Giostri.

Silva, R. da. (2018). Didática no Cárcere II: entender a natureza para entender o ser humano e o seu mundo. São Paulo: Giostri.

Thiollent, M. (2011). Metodologia da pesquisa-ação. São Paulo: Cortez. $18^{\mathrm{a}}$ ed. 